\title{
Synthesization of CNT on Surface of C/C Composites to Stabilize the Coefficient of Friction through a Wide Environmental Temperature Range
}

\author{
Kiyotaka Obunai ${ }^{1}$, Kazuya Okubo $^{2} \&$ Toru Fujii $^{2}$ \\ ${ }^{1}$ Faculty of Computer Scienece and System Engineering, Okayama Prefectural University, Soja, Japan \\ ${ }^{2}$ Department of Mechanical and Systems Engineering, Doshisha University, Kyotanabe, Japan \\ Correspondence: Kiyotaka Obunai, Faculty of Computer Scienece and System Engineering, Okayama \\ Prefectural University, Soja 719-1197, Japan. Tel: 81-86-694-9118. E-mail: obunai@cse.oka-pu.ac.jp
}

\author{
Received: September 13, 2012 Accepted: September 28, 2012 Online Published: October 16, 2012 \\ doi:10.5539/jmsr.v2n1p15 \\ URL: http://dx.doi.org/10.5539/jmsr.v2n1p15
}

\begin{abstract}
The purpose of this study is to stabilize the coefficient of friction of $\mathrm{C} / \mathrm{C}$ composites through wide environmental temperature range by synthesizing the carbon nanotubes (CNTs) on its surface. CNTs were synthesized on the surface of carbon-carbon $(\mathrm{C} / \mathrm{C})$ composites by the thermal chemical vapor deposition method. The coefficient of mutual friction between two flat specimens of both modified and unmodified $\mathrm{C} / \mathrm{C}$ composites were measured at a constant rotational speed under constant applied pressure by using disc-type test apparatus. The effect of CNT synthesization on the mutual friction coefficient and its dependence on test temperature were discussed. Frictional coefficient was high and also stable when the CNTs were synthesized on the surface while the test temperature was changed. The morphology evaluation of the frictional surface after the test suggested that synthesization of CNTs on a frictional surface of a $\mathrm{C} / \mathrm{C}$ composite was effective in changing the wear mode for stability of the coefficient of friction according to the change of environmental temperature.
\end{abstract}

Keywords: composites material, C/C composites, CNT, thermal CVD, friction coefficient

\section{Introduction}

A carbon-carbon $(\mathrm{C} / \mathrm{C})$ composite is known as one of the excellent composite materials because of its high mechanical properties, despite its low density, and also because of its high durability at high temperature environments (Manocha, 2003; Bussiba et al., 2008). Because of their excellent properties, C/C composites are applied not only to disc brakes of aerospace vehicles (Buchgraber, 2003; Don et al., 2009) but also to those of commercial vehicles such as motorcycles. Previous studies revealed that when the environmental temperature is low, the coefficient of mutual friction of $\mathrm{C} / \mathrm{C}$ composites is relatively low than that at high temperature (Yen et al., 1995, 1996; Gouider et al., 2004; Kasem et al., 2009). From the view point of reliable and safe performance, such dependence of frictional a coefficient on temperature should be cancelld for commercial vehicle application, in order to avoid the brake torque variation during braking (Obunai et al., 2006, 2009). In order to cancel the dependence of the frictional coefficient on temperature, metal infiltration methods have been applied to $\mathrm{C} / \mathrm{C}$ composites (e.g., C/C-SiC and C/C-Al) (Krenkel et al., 2002; Wang et al., 2006; Stadler et al., 2007; Zhang et al., 2007). However, after applying metal infiltration, the coefficient of mutual friction decreases from that of original $\mathrm{C} / \mathrm{C}$ composite, although its dependence on temperature was canceled. In order to improve the frictional behavior of the $\mathrm{C} / \mathrm{C}$ composite, it was recognized that a novel approach would be needed. The purpose of this study is to propose an effective technique for improving the coefficient of friction between the surfaces of a $\mathrm{C} / \mathrm{C}$ composite at low environmental temperatures so that this coefficient will be stable over a wide range of environmental temperatures.

To modify their surfaces, in this study, carbon nanotubes (CNTs) were, first, synthesized on C/C composites by thermal chemical vapor deposition (CVD). A commercially available $\mathrm{C} / \mathrm{C}$ composite was used as the base material for the synthesization of CNTs. The thin layers of $\mathrm{CoO}$ on $\mathrm{MoO}_{3}$ were prepared on the surface $\mathrm{C} / \mathrm{C}$ composite by a dip-coat method to promote CNT synthesization. The heated $\mathrm{C} / \mathrm{C}$ composite with thin layers was exposed to alcohol vapor. In this study, the time taken for introducing alcohol vapor into the oven was defined as the process time. The coefficient of mutual friction between two flat specimens of the modified and unmodified 
$\mathrm{C} / \mathrm{C}$ composites was measured at a constant number of revolutions under constant pressure by the disc-type test. The effect of CNT synthesization on the coefficient of mutual friction and its dependence on test temperature was discussed. In order to explain the reason for the improvement in the coefficient of mutual friction of modified $\mathrm{C} / \mathrm{C}$ composites by synthesization of $\mathrm{CNTs}$, the wear mode of modified $\mathrm{C} / \mathrm{C}$ composites was investigated.

\section{Experimental}

\subsection{Material}

In order to confirm the effectiveness of proposed technique, the commercially available $\mathrm{C} / \mathrm{C}$ composite (AC250: Across) was used as the base material for the synthesization of CNTs. Small plates, $20 \mathrm{~mm}$ square and $3 \mathrm{~mm}$ thick, were cut out.

\subsection{Support of Catalytic Metal}

In this study, a thin layer of $\mathrm{CoO}$ was prepared as the top surface of catalytic metal for CNT synthesization. Before the $\mathrm{CoO}$ layer was prepared, a base catalytic metal layer consisting by $\mathrm{MoO}_{3}$ was formed on the $\mathrm{C} / \mathrm{C}$ composite. The small plates of the $\mathrm{C} / \mathrm{C}$ composite described in the previous section were dipped into a solution of Mo-acetate, after heating at $400^{\circ} \mathrm{C}$ for $1 \mathrm{~h}$ in an electric oven filled with air, to eliminate impurities on the surface. To uniformly spread the catalytic metal on the $\mathrm{C} / \mathrm{C}$ composite, the plate was carefully lifted from the solution at a constant speed of $30 \mathrm{~mm} / \mathrm{min}$. Then, the plates were heated again in the oven at $400^{\circ} \mathrm{C}$ for $1 \mathrm{~h}$ to form a thin layer of $\mathrm{MoO}_{3}$ by oxidizing Mo-acetate on the surface. The same procedures were executed to support $\mathrm{CoO}$ on the surface of $\mathrm{MoO}_{3}$. The thicknesses of $\mathrm{CoO}$ and $\mathrm{MoO}_{3}$ were around $1 \mu \mathrm{m}$.

\subsection{Thermal CVD Procedure}

In this study, CNTs were synthesized by the thermal CVD method. Figures 1 and 2 show the thermal CVD equipment and the thermal CVD process used in this study, respectively. The specimens were heated in reductive gas $\left(\mathrm{Ar}: \mathrm{H}_{2}-3 \%\right)$ at the quartz tube, shown in the figure, from 25 (i.e., RT ) to $900^{\circ} \mathrm{C}$ at constant pressure of 5 $\mathrm{kPa}(\mathrm{abs})$, to deoxidize the catalytic metals on the surface of the specimen. When the temperature reaches $900^{\circ} \mathrm{C}$, alcohol vapor $\left(\mathrm{C}_{2} \mathrm{H}_{5} \mathrm{OH}\right)$ was introduced into the quartz tube and pressure was kept to $15 \mathrm{kPa}$, to promote the synthesization of CNTs (Mukul et al., 2010). After synthesization, the specimens were cooled again to RT in an inert atmosphere of Ar gas. In this study, the time spent introducing alcohol vapor into the oven was defined as the process time.

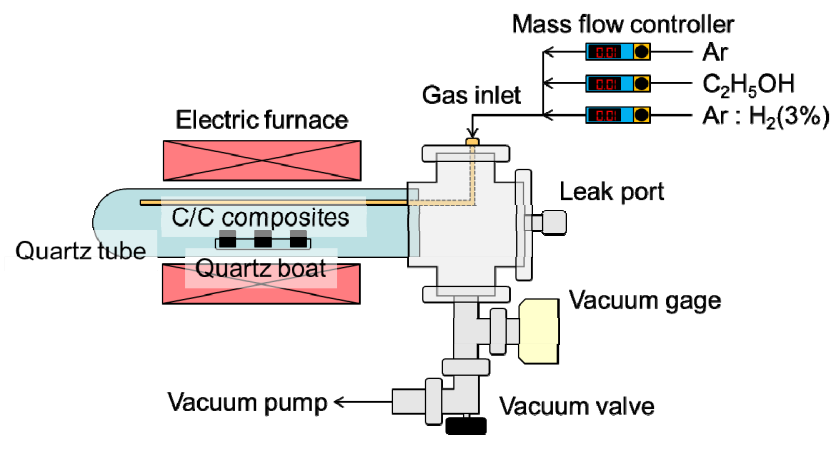

Figure 1. Thermal CVD equipment

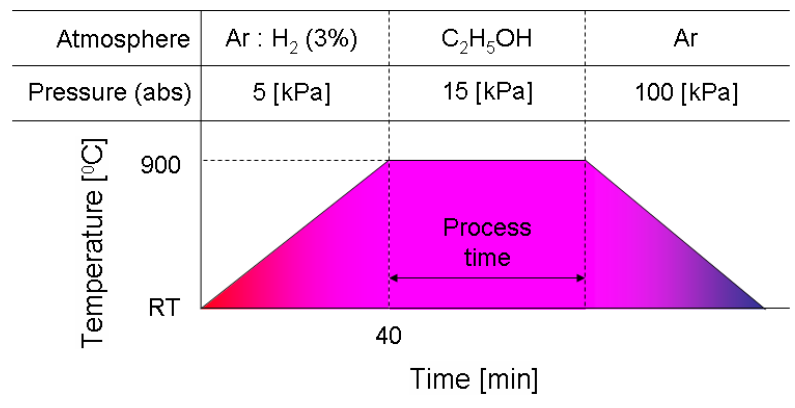

Figure 2. Thermal CVD process 


\subsection{Friction Test}

Figure 3 shows the configuration of a disc-type frictional tester. The specimen was set to the groove of the jig and rotated by the $\mathrm{AC}$ motor and another fixed specimen was pushed to the disc. The number of rotations of the specimen was controlled by an inverter at $100 \mathrm{rpm}(0.1 \mathrm{~m} / \mathrm{s}$ of sliding speed at effective radius). Constraint displacement was uniformly applied by the screw to apply $400 \mathrm{~N}(1.0 \mathrm{MPa})$ of normal force to the fixed specimen; the resultant force was measured by a load cell. The resultant torque was also measured to determine the coefficient of mutual friction between the two specimens.

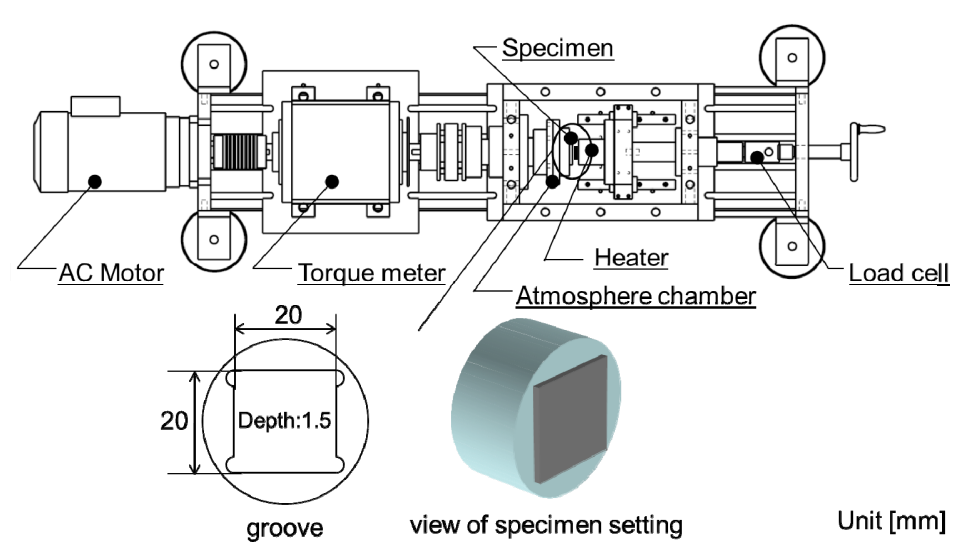

Figure 3. Rotational friction tester

\subsection{Micro Hardness Test}

The micro hardness of the CNT was measured by a micro hardness tester (SPH-1: Shimadzu) with a triangular pyramidal indenter (Murakami et al., 1997). In this study, the micro hardness was estimated by the diamond indenter applied to the thin film that was formed with the commercially available CNTs pressed under 9.5 MPa at $25^{\circ} \mathrm{C}$ for $3 \mathrm{~h}$. The indentation force was applied to the CNT film by a diamond indenter until the reaction force increased to $1500 \mu \mathrm{N}$ and maintaining a constant force speed of $85.60 \mu \mathrm{N} / \mathrm{s}$. The maximum load was held for $5 \mathrm{~s}$ and then released to zero at $85.60 \mu \mathrm{N} / \mathrm{s}$ force speed in the opposite direction. The micro hardness was determined by the following equation:

$$
H T_{115}=160.07 \times F / d^{2}
$$

Here, $H T_{115}, F$ and $d$ denote the micro-hardness, applied force and diagonal length of the indentation size on the specimen, respectively.

\section{Results and Discussion}

\subsection{Characterization of Synthesized CNTs on C/C Composites}

Figure 4(a)-(c) shows the state of the CNTs synthesized on the surface of the C/C composites, with each specimen having a different process time. It was confirmed that the CNTs (indicated by white arrows) were synthesized on the $\mathrm{C} / \mathrm{C}$ composite by the thermal CVD process. SEM observations suggested that both the diameter and length of spike-like CNTs increased according to the process time for the synthesization of the CNTs. The diameters of CNTs were increased from around 80 to $280 \mathrm{~nm}$ according to the process time from 15 to $45 \mathrm{~min}$. The lengths of CNTs were also increased from around 2.7 to $4.8 \mu \mathrm{m}$. 


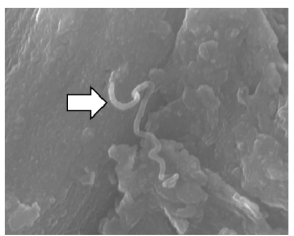

(a)

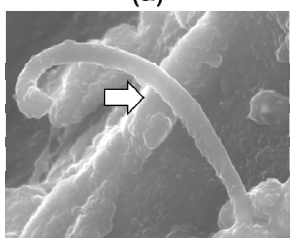

(c)

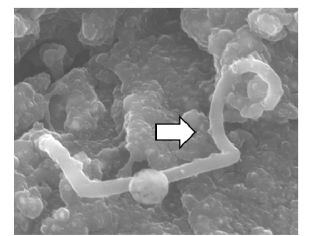

(b)

$$
100 \mathrm{~nm}
$$

(a) : process time $=15$ [min]

(b) : process time $=30$ [min]

(c) : process time $=45[\mathrm{~min}]$

Figure 4. SEM photographs of synthesized CNTs with different synthesized process times

To evaluate the result of synthesization, in this study, an effective parameter of $C_{C N T}$ was introduced by authors, as described by the following equation:

$$
C_{C N T}=\left(m_{C V D}-m_{R}+C_{y}\right) / A_{S}
$$

Here, $C_{C N T}$ denotes concentration of the synthesized CNTs per unit surface area, $m_{C V D}$ is mass of specimen after CVD, $m_{R}$ is the mass before CVD, $C_{y}$ is the dissipated mass by CVD process, and $A_{S}$ denotes the surface area of the specimen. The dissipated mass of $C_{y}$ was depend on the hermetic performance of the CVD apparatus. In this study, the $C_{y}$ value was determined by measuring the mass loss during the CVD process without introducing of alcohol vapor. Figure 5 shows the concentration of the synthesized CNTs per unit surface area with respect to process time for synthesization. The Concentration of the synthesized CNTs increased from about 0.0033 to $0.0044 \mathrm{mg} / \mathrm{mm}^{2}$ with the process time. CNT diameter and length increased with the concentration of synthesized CNTs when the process time of synthesization was extended.

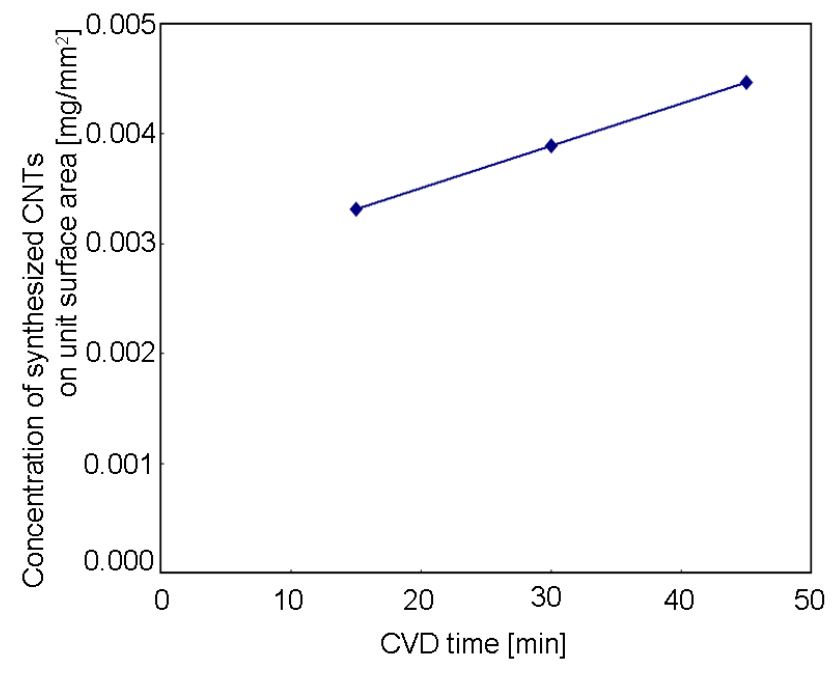

Figure 5. Concentration of synthesized CNTs per unit area with respect to synthesized time

\subsection{Effect of CNT Synthesization on Coefficient of Friction}

Figure 6 shows the coefficient of mutual friction of the modified $\mathrm{C} / \mathrm{C}$ composites with respect to the concentration of the synthesized CNTs per unit surface area at RT condition. For comparison, the figure also shows basic data of the coefficient of mutual friction for unmodified $\mathrm{C} / \mathrm{C}$ composites, indicated by a dashed line $(\mu=0.11)$. At RT, it was confirmed that the coefficient of mutual friction was improved from 0.17 to 0.32 by the synthesization of the CNTs on the frictional surface of the $\mathrm{C} / \mathrm{C}$ composite. 


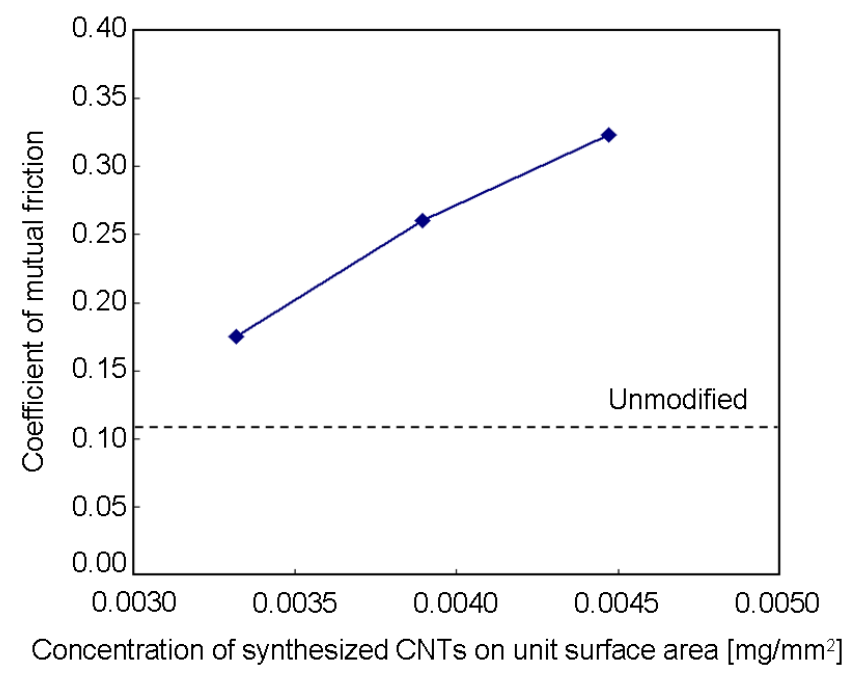

Figure 6. Coefficient of mutual friction of modified $\mathrm{C} / \mathrm{C}$ composites with respect to concentration of synthesized CNTs per unit area

Figure 7 also shows the coefficient of mutual friction of the modified and unmodified $\mathrm{C} / \mathrm{C}$ composites with respect to the test temperature. The coefficient of mutual friction at low environmental temperatures increased with an increase in the concentration. The dependence of the coefficient of mutual friction $\left(\Delta \mu=\mu_{\max }-\mu_{\min }\right)$ on test temperature was cancelled from 0.23 to 0.06 with an increase in the concentration of the synthesized CNTs per unit surface area (unmodified: $\Delta \mu=0.23$ ).

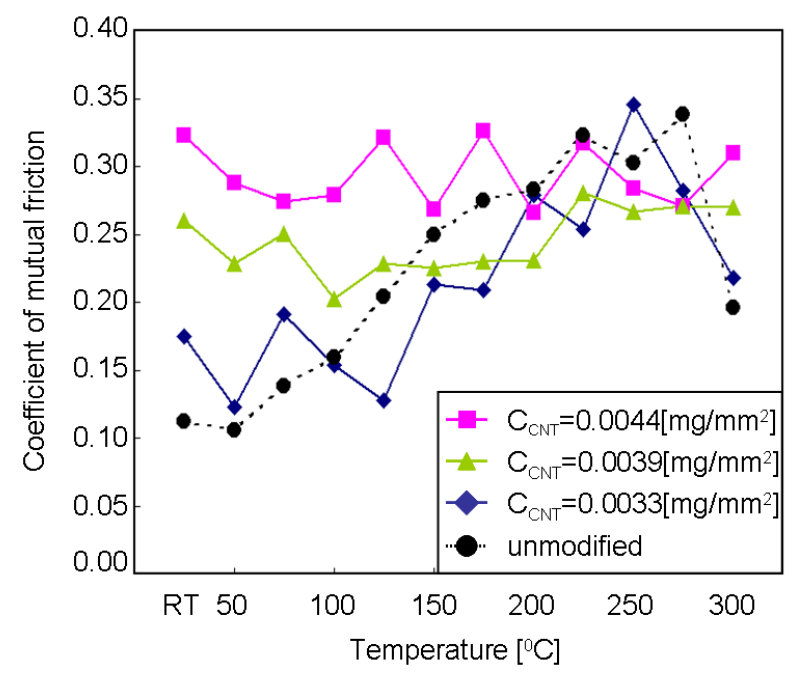

Figure 7. Coefficient of mutual friction of $\mathrm{C} / \mathrm{C}$ composites with respect to test temperature

\subsection{Durability of Synthesized CNTs}

Figure 8 shows the coefficient of mutual friction of the modified $\mathrm{C} / \mathrm{C}$ composites with respect to the testing time at RT condition. The figure also shows basic data of the coefficient of mutual friction for unmodified $\mathrm{C} / \mathrm{C}$ composites, indicated by a dashed line $(\mu=0.11)$. Test result showed that when the surface of $\mathrm{C} / \mathrm{C}$ composite was modified with excessive CNTs $\left(\mathrm{C}_{\mathrm{CNT}}=0.0044 \mathrm{mg} / \mathrm{mm}^{2}\right)$, the coefficient mutual friction was rapidly decreased as same value as unmodified composites. However, when moderate $\mathrm{CNTs}\left(\mathrm{C}_{\mathrm{CNT}}=0.0039 \mathrm{mg} / \mathrm{mm}^{2}\right)$ were synthesized on surface, the improvement of coefficient of mutual friction was still remaining even after 300 sec. 


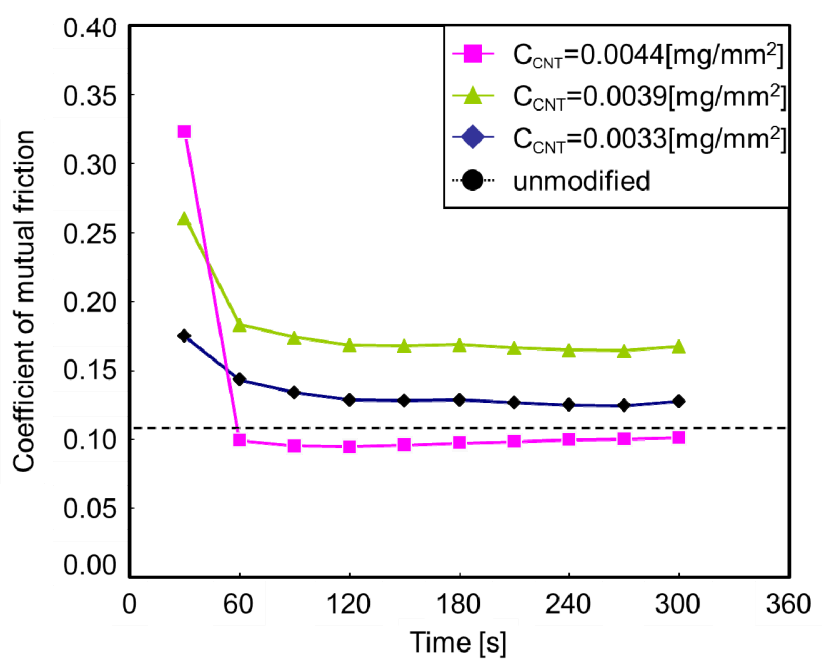

Figure 8 . Durability of synthesized CNTs

\subsection{Effect of Synthesized CNTs on Wear Mode}

Figure 9 shows the difference of observed micro hardness in the CNT and in the original C/C composite. The observed micro hardness of the $\mathrm{CNT}\left(\mathrm{HT}_{115}=156\right)$ was almost five times that of the original $\mathrm{C} / \mathrm{C}$ composite $\left(\mathrm{HT}_{115}=34\right)$.

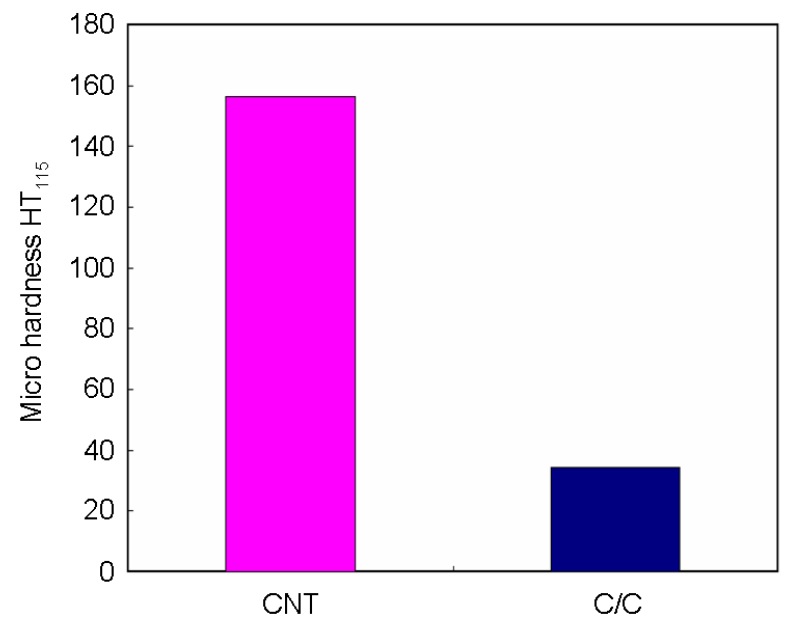

Figure 9. Comparison of hardness of $\mathrm{CNT}$ and $\mathrm{C} / \mathrm{C}$ composites

Figures 10 shows the worn surfaces of the unmodified and modified $\mathrm{C} / \mathrm{C}$ composites after the frictional test was performed at conditions of RT and $300^{\circ} \mathrm{C}$ (i.e., HT), respectively. The rough worn surface was observed at all conditions of elevated temperature. However, a flat surface was observed at RT when the surface of the $\mathrm{C} / \mathrm{C}$ composite was unmodified. On the other hand, a rough surface was observed on the worn surface of the modified $\mathrm{C} / \mathrm{C}$ composites, when the test temperature was low. These results suggest that tiny, hard CNTs on a frictional surface promote abrasive wear of the modified $\mathrm{C} / \mathrm{C}$ composites. In order to explain why the coefficient of mutual friction of the modified $\mathrm{C} / \mathrm{C}$ composites increased with an increase in the concentration of the synthesized CNTs per unit surface area, the observed average area of the synthesized CNTs in the sliding direction was determined by stereoscopic analysis using SEM images, in which images were investigated in different directions.

Figure 11 shows the change in the observed average area of the synthesized CNTs in the sliding direction with respect to the concentration. The observed average area increased from 223 to $1154 \mu \mathrm{m}^{2}$ with an increase in the concentration of the synthesized CNTs per unit area. These results suggest that the frictional force due to 
scratching by the CNTs increases with an increase in the concentration of the synthesized CNTs. This study found that the synthesization of CNTs on the frictional surface of $\mathrm{C} / \mathrm{C}$ composites was effective for changing the wear mode for stability of the coefficient of friction according to the environmental temperature changes.

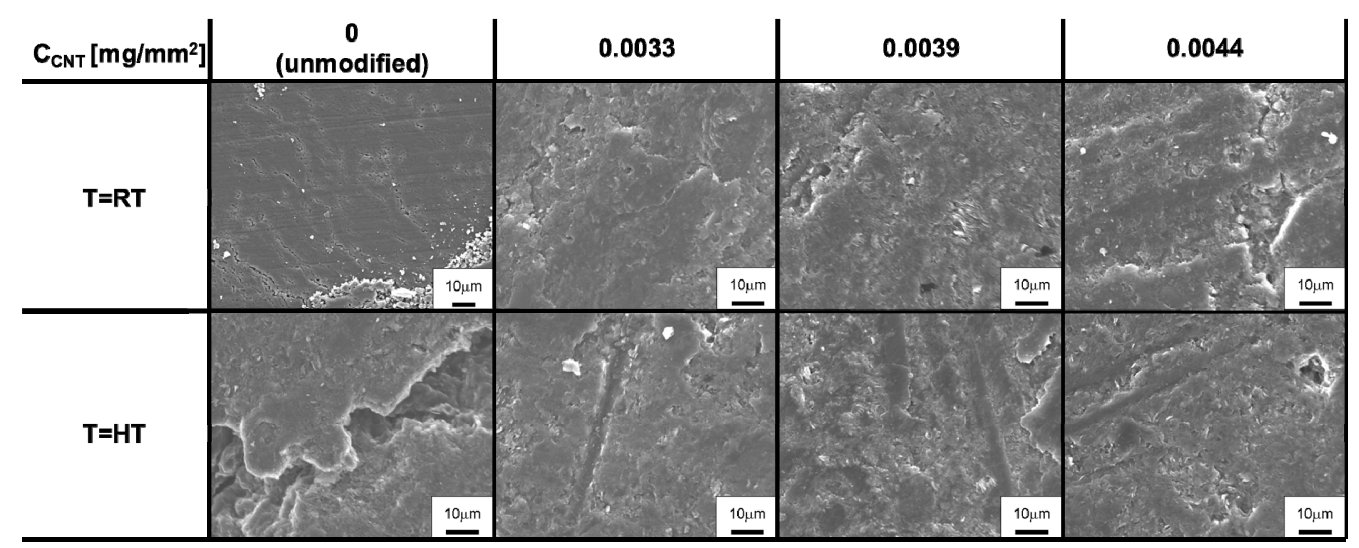

Figure 10. Worn surface of unmodified/modified C/C composites after test performed at RT/HT

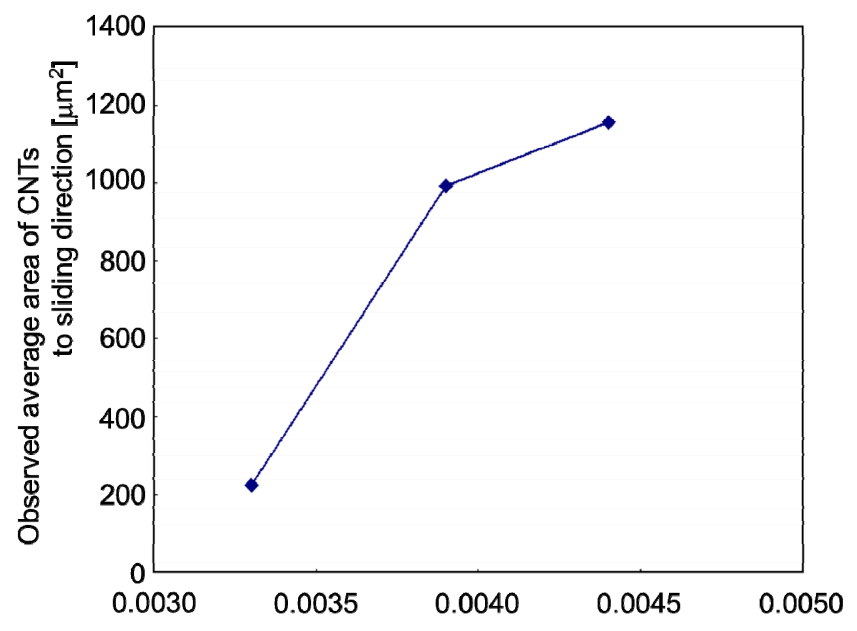

Concentration of synthesized CNTs on unit surface area $\left[\mathrm{mg} / \mathrm{mm}^{2}\right]$

Figure 11. Observed average area of synthesized CNTs in sliding direction with respect to concentration of synthesized CNTs per unit surface area

\section{Conclusions}

In this study, the carbon nano tubes (CNTs) were synthesized on the surface of commercially available C/C composites and its effect of mutual friction was investigated. The following conclusions were given.

1) The diameter and length of spike-like CNTs increased according to the concentration of synthesized CNTs per unit surface area when the process time was extended for synthesization.

2) The dependence of the coefficient of mutual friction on the test temperature was almost canceled with an increase in the concentration of synthesized CNTs per unit surface area.

3) The durability of synthesized CNTs were depending on the concentration of synthesized CNTs per unit surface area.

4) The synthesization of CNTs on the frictional surface of $\mathrm{C} / \mathrm{C}$ composites was effective in changing the wear mode for stability of the coefficient of friction according to change in environmental temperature. 


\section{Acknowledgements}

The authors would like to express thanks to the Japan Society for the Promotion of Science for their generous funding during the research and writing of this paper.

\section{References}

Buchgraber, W. (2003). Carbon/Carbon composite friction discs for aerospace. Mat-wiss. u. Werkstofftech, 34, 317-321. http://dx.doi.org/10.1002/mawe.200390067

Bussiba, A., Kupiec, M., Piat, R., \& Bohlke, T. (2008). Fracture characterization of C/C composites under various stress modes by monitoring both mechanical and acoustic responses. Carbon, 4, 618-630. http://dx.doi.org/10.1016/j.carbon.2008.01.020

Don, J., \& Wang, Z. (2009). Effect of anti-oxidant migration on friction and wear of C/C air craft brakes. Appl. Compos. Mat., 16, 73-81. http://dx.doi.org/10.1007/s10443-008-9075-1

Gouider, M., Berthier, Y., Jacquemard, P., Rousseau, B., Bonnamy, S., \& Estrade-Szwarckopf, H. (2004). Mass spectrometry during $\mathrm{C} / \mathrm{C}$ composite friction: carbon oxidation associated with high friction coefficient and high wear rate. Wear, 256, 1082-1087. http://dx.doi.org/10.1016/S0043-1648(03)00534-9

Kasem, H., Bonnamy, S., Berthier, Y., Dufrenoy, P., \& Jacquemard, P. (2009). Tribological, phisicochemical and thermal study of the abrupt friction transition during carbon/carbon composite friction. Wear, 267, 846-852. http://dx.doi.org/10.1016/j.wear.2008.12.076

Krenkel, W., Heidenreich, B., \& Renz, R. (2002). C/C-SiC composites for advanced friction systems. Adv. Eng. Mat., 4(7), 427-436. http://dx.doi.org/10.1002/1527-2648(20020717)4:7<427::AID-ADEM427>3.0.CO;2-C

Manocha, L. M. (2003). High performance carbon-carbon composites. Sadhana, 28, 349-358. http://dx.doi.org/10.1007/BF02717143

Mukul, K., \& Yoshinori, A. (2010). Chamical Vapor Deposition of Carbon Nanotubes: A Review on Growth Mechanism and Mass Production. J. of Nanoscience and Nanotechnology, 10, 3739-3758. http://dx.doi.org/10.1166/jnn.2010.2939

Murakami, Y., \& Itokazu, M. (1997). Elastic-plastic analysis of a triangular pyramidal indentation. Int. J. of Solids and Structures, 34(30), 4005-4018. http://dx.doi.org/10.1016/S0020-7683(97)00001-2

Obunai, K., Okubo, K., Fujii, T., \& Nakatsuji, T. (2006). Study on low speed judder of wave type brake disc for motorcycles. SAE paper, 2006-32-0026. http://dx.doi.org/10.4271/2006-32-0026

Obunai, K., Okubo, K., Fujii, T., \& Nakatsuji, T. (2009). Characterization of brake torque variation of wave type brake disc for motorcycles. SAE paper, 2009-01-3023. http://dx.doi.org/ 10.4271/2009-01-3023

Stadler, Z., Krnel, K., \& Kosmac, T. (2007). Friction behavior of sintered metallic brake pads on a C/C-SiC composite brake disc. J. of the European Society, 27, 1411-1417. http://dx.doi.org/10.1016/j.jeurceramsoc.2006.04.032

Wang, T. C., Fan, T. X., Zhang, D., \& Zhang, G. D. (2006). Fabrication and the wear behaviors of the carbon/aluminium composites based on wood templates. Carbon, 44, 900-906. http://dx.doi.org/10.1016/j.carbon.2005.10.022

Yen, B. K., \& Ishihara, T. (1995). On temperature-dependent tribological regimes and oxidation of carbon-carbon composites up to $1800^{\circ} \mathrm{C}$. Wear, $254-262$. http://dx.doi.org/10.1016/0043-1648(95)06903-8

Yen, B. K., \& Ishihara, T. (1996). An investigation of friction and wear mechanisms of carbon-carbon composites in nitrogen and air at elevated temperatures. Carbon, 34(4), 489-498. http://dx.doi.org/10.1016/0008-6223(95)00205-7

Zhang, J., Xu, Y., Zhang, L., \& Cheng, L. (2007). Effect of braking speed on friction and wear behaviors of C/C-SiC composites. Int. J. Appl. Ceram. Technol., 4(5), 463-469. http://dx.doi.org/10.1111/j.1744-7402.2007.02155.x 